\title{
Psychodynamic Psychotherapy: Healing Attachment Wounds
}

Kathleen Wheeler

\section{PERSONAL EXPERIENCE WITH PSYCHODYNAMIC PSYCHOTHERAPY}

Soon after completing my master's and doctoral degree in advanced practice psychiatric nursing at New York University in the mid-1980s, I wanted to start my own private practice. However, I knew that in order to gain the clinical skills and confidence for this enterprise, I needed first to get more training in psychotherapy. I decided to apply to a 4-year psychoanalytic program at The Training Institute for Mental Health in New York City. Notably, I was the first nurse to apply and be accepted by this institute. Following this rigorous program, which required 4 years of coursework, my own personal analysis three to four times per week, a 10-hour caseload of patients at the Institute weekly, and supervision three times a week, I felt ready to see patients on my own.

\section{FOUNDER OF PSYCHODYNAMIC PSYCHOTHERAPY}

Psychodynamic psychotherapy is derived from psychoanalytic psychotherapy, which was developed by Sigmund Freud at the end of the 19th century. Sigmund Freud's classic model of psychoanalytic psychotherapy is based on drive theory; that is, that all behavior is determined by unconscious forces or instincts, either sexual or aggressive. Freud's structural model of the id, ego, and superego explains the idea of psychic conflict. That is, symptoms are thought to develop through a conflict between an instinctual wish (id) and the person's defense against the wish (ego). The superego is part of the unconscious that is formed through internalization of moral standards of parents and society and acts to censor and restrain the ego. Freud delineated the psychosexual stages of development based on the idea that libidinal energy shifts between various erogenous zones in each stage. The concept of psychic determinism is embedded within this model and refers to the idea that nothing happens by chance; everything on a person's mind and all behavior, pathological and nonpathological, has a cause, and is determined by multiple factors. 
Freud's seminal ideas have contributed to the evolution of many different psychodynamic schools of thought. Each psychodynamic model evolved from previous approaches while establishing a new perspective that placed different emphases on human development and motivation for behavior. Each psychodynamic school of thought that followed - that is, ego psychology, interpersonal analysis, object relations, Lacanian psychoanalysis, intersubjectivity, and relational and attachment-based psychotherapy-developed its own theoretical constructs and techniques. The evolution of Freudian thought parallels paradigm shifts in science in the 20th century from Freudian drive theory to relational, intersubjective, and attachment models, with each contributing theory about what constitutes motivation for human behavior.

\section{DEFINITION OF MENTAL HEALTH AND PSYCHOPATHOLOGY}

Underpinnings of psychodynamic therapy are rooted in developmental theory, with the basic premise that what has happened in the past determines what the person is doing today. It is posited that through understanding these factors and the unconscious, the individual is empowered and then free to make more conscious decisions and consequently live a more satisfying and useful life. Thus, the mentally healthy person is able to regulate their anxiety, be in relationships, make conscious decisions, and live a satisfying, useful life. The mentally healthy person is succinctly stated in Freud's wellknown phrase "the ability to love and to work."

Historically, psychodynamic schools emphasize the centrality of conflict among powerful desires, wishes, and fears. Psychopathology arises when there is a conflict among desires, wishes, and fears. This may arise from any developmental level and symptoms develop as a result from problems occurring during any phase of development. Freud posited that if a person has not successfully negotiated the previous stage, specific problematic character traits or psychopathology is thought to continue throughout life. More recent psychodynamic theorists stress the importance of relationship in the development of mental health and illness.

\section{THERAPEUTIC GOALS IN PSYCHODYNAMIC PSYCHOTHERAPY}

Psychodynamic psychotherapy can be seen as a continuum from supportive psychotherapy to expressive psychotherapy to psychoanalytic psychotherapies. The goals and focus of each type of psychodynamic psychotherapy differ. The goals for the supportive end of the continuum are aimed toward stabilization through restoring functioning, reducing anxiety, strengthening defenses, and facilitating more effective problemsolving, whereas the psychoanalytic end is aimed toward processing through interpreting unconscious conflict and gaining insight (Gabbard, 2017).

Most clinicians believe that the decision to use supportive psychodynamic psychotherapy should be based on the person's ego strength and weaknesses, present coping skills, highest level of functioning previously achieved, recent losses, and other life stresses and circumstances. McWilliams (2011) states that the overall goal for expressive psychodynamic psychotherapy is the development of an integrated, complex, and positively valued self. This means that the person is able to tolerate ambivalent feelings and self-regulate emotions. The goal for psychoanalytic psychotherapy is resolution of the transference neurosis and effecting deep personality or trait change. The transference neurosis is an intense repetition of childhood conflicts, where the patient re-experiences feelings that originally developed in relation to the parent but now are felt toward the 
therapist because of the frequency and intensity of the sessions. The degree to which the therapy is supportive versus psychoanalytic is based on the focus of transference issues and the frequency of sessions (Gabbard, 2017).

In moving toward the psychoanalytic end of the continuum, as the transference deepens, the focus on interpretations increases, as does the number of sessions per week. Through transference, unconscious conflicts are illuminated and then worked through. Those who embark on psychoanalytic psychotherapy need the time and resources to invest in several sessions per week and treatment may require several years. These individuals are often in training to be psychoanalysts and need to be in their own analysis as part of their training program.

\section{PERSPECTIVE ON ASSESSMENT IN PSYCHODYNAMIC PSYCHOTHERAPY}

Assessment of ego functioning, relationships, and attachment style are all important in formulating a treatment plan for psychodynamic psychotherapy. See Chapters 3 and 5 in Wheeler (2022) for specific assessment tools to measure these constructs. Ego functioning refers to components of executive functioning such as self-awareness, problemsolving, memory, adaptability, affect regulation, and interpersonal functioning. Like the solid foundation of a well-built house, ego strength supports the individual in the pursuit of life goals, dreams, and ambitions, especially during times of trouble. It ensures coping abilities, provides an individual with a sense of identity, can be recognized during initial assessment and throughout therapy, and increases as patients grow in maturity (Bjorklund, 2000). To the degree each ego function can be identified and assessed in the clinical situation, ego strength can be acknowledged, rated, reinforced, supported, built upon, or "loaned" to some degree to lower-functioning patients by their relatively higher-functioning therapists in the process of identifying with the therapist's own ego strength (Bjorklund, 2000).

Developmental theories and the level of defenses are also considered in order to determine what type of psychodynamic therapy should be offered. In assessing ego strength, it is important to identify the primary defenses the person uses to ward off anxiety. McWilliams (2011) lists the types of defenses most commonly associated with those in the psychotic level of personality organization and identifies these defenses as originating early in development. These include denial, projection, splitting, primitive idealization and devaluation, withdrawal, omnipotent control, and dissociation. These defenses protect the person who is terrified of annihilation, who lacks a basic security in the world, and who is vulnerable to psychotic disorganization. Those on this end of the developmental continuum struggle with identity issues and confusion about who they are. Even if not overtly psychotic, the person is thought to be functioning at the symbiotic level of development, with little self-other differentiation. A therapeutic focus based on the assessment provides a realistic expectation for treatment. This flows from conceptualizing presenting issues developmentally and understanding intrapsychic conflict. See Figure 1.1 for components of a psychodynamic case formulation.

\section{THERAPEUTIC INTERVENTIONS IN PSYCHODYNAMIC PSYCHOTHERAPY}

The job of the psychodynamic therapist is to help the person understand both how fears and inhibitions in early life have led him or her to react to healthy feelings as if they were a threat and how the resulting anxiety plays an active role in generating his or her difficulties in the present. The person inadvertently and consistently brings about 


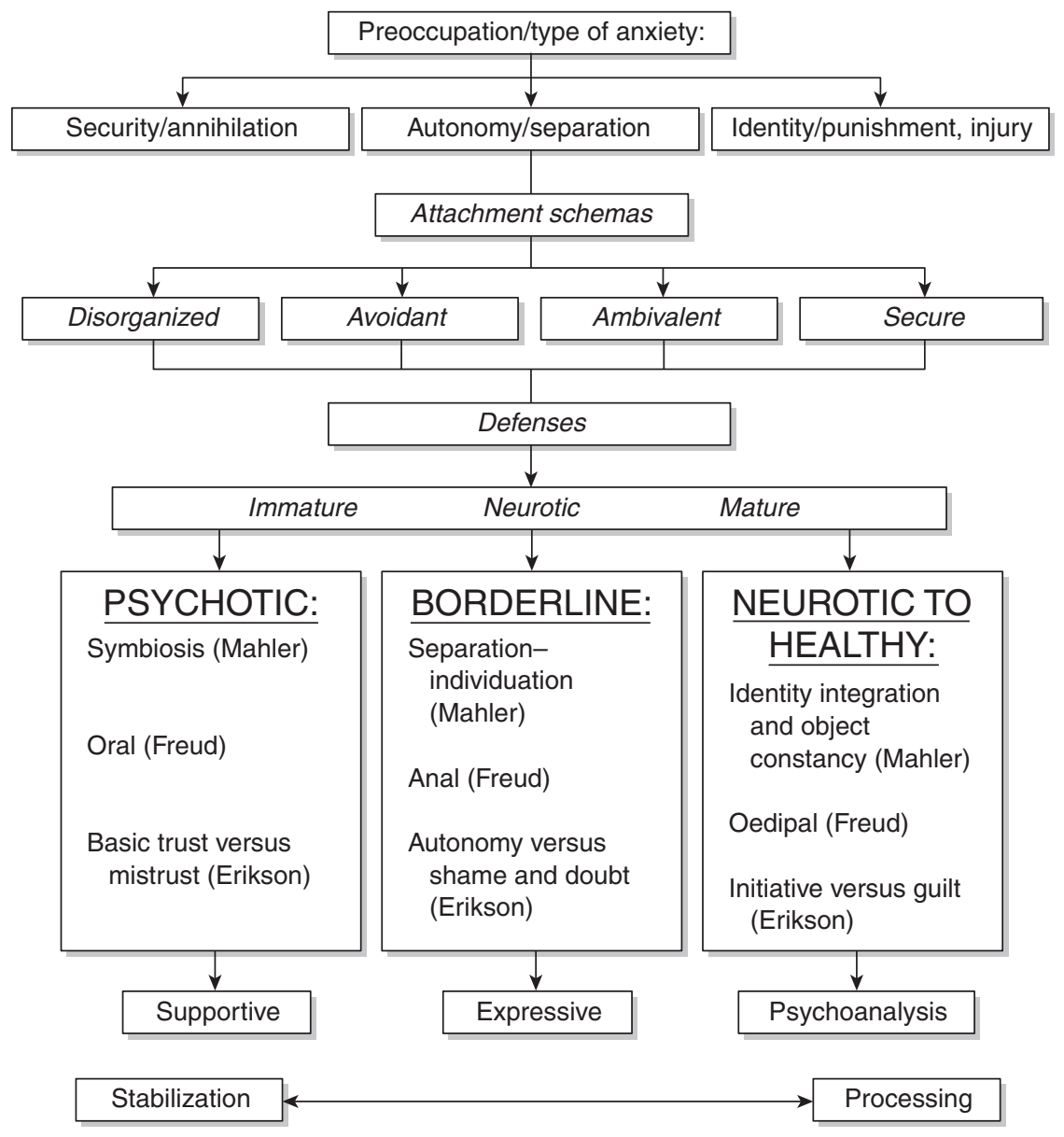

FIGURE 1.1 Case formulation and psychodynamic therapy algorithm.

Source: Reproduced from Wheeler, K. (2021). Psychotherapy for the advanced practice psychiatric nurse: A how-to guide for evidence-based practice (3rd ed.). New York, NY: Springer Publishing Company.

consequences that are not consciously intended. For example, the person who is fearful of feelings of anger may act overly nice, unassertive, and maintain a passive stance toward others. This allows others to ignore his or her needs and, consequently, he or she begins to feel frustrated and devalued, which leads to more anger and more anxiety, and the pattern is repeated. Another example is a person who fears hostility from others because it triggers their experience with an early unsafe caretaking environment. Thus, the person interprets every interaction as potentially hostile, then preemptively enacts self-protective hostility toward others, which evokes hostility from them, which leads to more anxiety (Wachtel, 2011).

The psychodynamic therapist uses interpretations to expose the person to previously avoided experiences while offering empathy in a safe, therapeutic environment. Interpretations are important in order to assist the person in deepening their understanding of their motivations, feelings, and how they needed to obscure the threatening aspects of their caretaker. Therapeutic interpretations are not just aimed toward intellectual understanding, but also emphasize the facilitation of emotional experiencing at a gradual pace. Re-experiencing painful affect allows adaptive processing so that 
dissociated or disconnected memory networks can be integrated with other, more adaptive neural networks (Cozolino, 2017). The emphasis is on the past and past relationships; focus on the expression of emotion; identification of patterns in actions, thoughts, feelings, experiences, and relationships; exploration of and working with resistances that impede treatment; exploration of intrapsychic issues through asking about dreams; and a focus on the transference and the working alliance. The therapist needs to remain cognizant that the patient may in reality have been in an unsafe environment.

\section{CASE STUDY}

\section{Background}

Michelle is a single 28-year-old woman from France and a full-time student majoring in creative writing and journalism who works part-time as a waitress in New York City. Her parents and two older siblings live in France. She sought treatment after returning to New York from a visit home because she felt "confused, depressed, and was losing control." She lived with her boyfriend for the past 2 years and things were not working out as he "wanted his freedom" and was going out with other women. Michelle's anxiety reached panic proportions when she was alone in her apartment and she began to fear being attacked and possibly raped. These feelings left her breathless with heart palpitations. It was these episodes that brought Michelle into treatment.

Michelle reported that her father is an angry, impulsive, verbally abusive, and critical man who would scream and explode over trivial incidents. She was never sure how to please him. However, she idealized him as he was there in a way for her that her mother never was there for her. Her mother's unavailability and absence were a constant theme in her memories of her childhood. She believes that her mother did not like her and recounted many childhood memories of waiting for her mother who did not come home or pick her up when she was supposed to from school. Even when Michelle's mother was there physically, she says that her mother was never there emotionally. Michelle describes the frequent headaches and illnesses of her mother, which kept her in bed for days with Michelle playing a caretaking role for her mother. Her mother would often cry unconsolably in Michelle's arms when her mother felt her lovers were abandoning her. Michelle found letters when she was 8 years old from her mother to her lover and remembered crying for days; however, upon confronting her siblings about the letters, she learned that everyone already knew about her lover and that her mother had had other affairs before this. Her father agreed with Michelle that her mother was never there for her. Michelle remembers no happy memories of childhood but remembers always crying and wanting attention.

Throughout her childhood Michelle suffered from constipation and intestinal pain. After many diagnostic tests, she had an appendectomy but then was told nothing was wrong with her appendix and it was all in her head. During early adolescence, Michelle said she was very promiscuous and had many one night stands, often with her older sister's friends. She drank a lot of alcohol and smoked marijuana, coming home many nights drunk and/or stoned. At the age of 17, Michelle was so distraught that she stood on a window ledge threatening to commit suicide. It was after this that she sought therapy for the first time but had to quit after a few months because her father said he would not pay for it. Between the ages of 17 and 18, she was bulimic, eating the pies her mother made and then throwing up. At age 19, she came to New York City to work as an au pair for an American family. Shortly after this, she was mugged and raped by a man who told her he was a policeman. 


\section{Psychodynamic Formulation}

Michelle's history of maternal deprivation left her hungry for love and affection and with deep feelings of worthlessness. Although her father was there for her at times, he was an angry, domineering man who demanded perfection. Michelle's superego is harsh as she is hard on herself and has internalized and identified with her demanding, critical father. Michelle was scapegoated in her family by her older siblings who told her she was stupid and fat and made fun of her for crying all the time. Her sister and brother would discipline Michelle; for example, slapping her hands when she bit her nails. Being a victim has been a constant theme throughout her life. Her masochism is multidetermined. Preoedipal issues are apparent in her neediness, demandingness, and fragility. She describes herself as attention-seeking, social, and provocative in relationships. She states that she is desperate for love and so needy that she goes along with anything, and then begins to feel used. She then becomes demanding, angry, and provocative, which may be an attempt to turn the tables, gain control, and get even with those who have hurt her. Michelle described her relationship with her boyfriend as a fantasy, in which she demanded affection and was so emotionally needy that she turned him off. He told her: "You need someone to take care of you." It was toward the end of this 2-year relationship when Michelle sought treatment.

Major defenses for Michelle include denial and projection. Her need to control others and paranoia that she might be hurt may in part be due to her rage toward her mother and father, which is projected onto others. Her idealization of her father and her belief that her mother would be there for her despite her constant unavailability demonstrate her use of denial. Michelle's repression is apparent in her inability to remember many details of her childhood. Her search for love is about suffering and pain. Being given attention from the loved one even if the attention is negative becomes all consuming.

Developmentally, Michelle experienced her childhood in a depriving, turbulent milieu and her parents' stormy marriage served to heighten and exacerbate Michelle's infantile conflicts. Her early needs may not have been met adequately by either parent. Her oral hunger is apparent in her demanding, dependent, love-seeking behavior, while her negativism and difficulty maintaining her own autonomy reflects unresolved anal developmental issues. Michelle's unavailable, absent mother contributed to her sense of defectiveness, inadequacy, and shame. Persistent intense anxiety permeates most aspects of her life. In her mother's absence, psychically as well as physically, Michelle turned to her father, who forced her to go along with his wishes; thus, her struggle for autonomy was thwarted. In the context of her mother's absence, she took her mother's place and filled in socially and emotionally her mother's role with her father. Thus, she was the oedipal victor winning her father's love and attention.

A secure attachment to her mother was threatened because she could not count on her mother to be there for her. All children need to feel safe in order to survive. This type of attachment pattern can be conceptualized as ambivalent/anxious. Ambivalent/anxious attachment results in the person feeling insecure; difficulty with separation; difficulty being soothed upon reunion; too much anxiety due to the caregiver's unreliability; high emotionality that interferes with functioning; and confusion about the integrity of relationships in the present. This left Michelle with deep feelings of defectiveness and the false-negative belief that there was something wrong with her. This was a safer position for her than recognizing that her life was in danger. It would cause even greater anxiety for a child to let in the reality that perhaps they are not cared about as they should be, and due to the child's normal cognitive immaturity (Piaget, preoperational, magical thinking), the child concludes that the emotional or physical abuse occurs because they caused it to happen. Thus, it is the child's fault if there is chaos and neglect, which then preserves the image of the parents as loving and benevolent. This is a safer conclusion 
for the child, so they feel they have some control over the situation. As a result, Michelle had pervasive feelings of guilt and low self-esteem without consciously understanding to what these feelings were connected.

It is important to note that Michelle's early years were nurturing enough in that some self-object differentiation was attained. She has received scholastic honors this year in college and has been able to work and live productively in a foreign country, which attests to her ego functioning.

\section{Treatment and Goals}

Michelle came to her sessions one to three times a week over the next 2 years for psychodynamic psychotherapy. Psychodynamic techniques employed were analysis of resistance and transference, dream interpretation, free association, clarification, observation, reflection, and analysis of defenses. Goals of treatment included (a) to develop a working alliance; (b) to understand and interpret transferences when necessary; (c) to enlarge the sphere of Michelle's observing ego; (d) to assist Michelle in modifying her overly harsh superego; (e) to assist in the development of healthier defenses; (f) to help Michelle in the working through of her rage toward her mother and father; $(\mathrm{g})$ to aid Michelle in the process of gaining insight and acceptance of her mother's absence; (h) to assist in the transfer of the soothing function of the therapist; (i) to promote autonomy of Michelle's ego from drives; and (j) to attain at greater level of self-object differentiation.

Michelle's pervasive sadness and anxiety were in the foreground the first year of treatment with major themes of intense neediness and her ensuing struggle to obtain love and safety. She was conflicted about seeking help in psychotherapy. On one hand, seeking and asking for help was difficult for Michelle as she had been encouraged to be independent from an early age and ridiculed when she requested assistance from her parents. On the other hand, Michelle felt that others should know what she wanted without her telling them. The latter is rooted in the early mother-child interaction and wish for symbiotic oneness with the all-giving mother. As the treatment process unfolded, a transference evolved with Michelle needing me to mirror and validate her experiences for her. She felt I should know what she wanted. On a more latent level, being close to another person meant she would be abandoned, and she felt she could not rely on anyone to be there for her. Michelle fought the ensuing regression triggered by therapy in an effort to avoid the inevitable hurt and disappointment which she felt would result from counting on me.

In exploring deeper into Michelle's feelings of anxiety, she realized how bitter and angry she felt toward her mother for not being there for her as she had needed. This was demonstrated in a provocative, angry stance toward others. She recounted that she cried from age 8 until 19 and was often inconsolable. Sessions early in treatment focused on the many instances in her childhood when her mother had not been there for her. Tearful and angry, Michelle mourned the loss of her mother. As she understood and felt her anger, her anxiety lessened and she had no further panic attacks.

After 6 months of treatment, I told Michelle about my upcoming vacation in August. She replied that she needed a break anyhow and wanted space. She felt angry about coming for her sessions and thought it was a waste of time. She sadly remembered as a little girl wanting desperately for someone to listen to her. Michelle would invite herself over to her friend's home to stay overnight, but her friend would want to be alone. Michelle would feel so hurt and would beg her friend to allow her to stay anyway, which she did and then Michelle would feel even worse as her friend would ignore her. Michelle felt that her boyfriend needed his space and that something was missing. He was not there for her in the way she needed him to be. I asked Michelle whether she felt 
I too needed my space and would not be there for her as I was going on vacation. She denied caring whether I was there or not and left slamming the office door.

The next session Michelle felt confused, moody, and sad. She was angry at work and felt that she could not count on anyone. She had entertained a houseguest from France and felt taken advantage of by him . . . he was not there for her and not supportive. As her litany of grievances mounted, I gently asked if she could be talking about how she felt here too? That I would not be there for her and that she felt she could not count on me? Tearfully, Michelle said she thought it was too important to her to come here and that it had become a part of her life. This was Michelle's first acknowledgment of transferential feelings and I felt it was an important step in her therapy. Michelle spent the next several sessions talking about her mother and her feelings that she had not been wanted. Michelle knew her mother had an abortion after she was born, and also felt that she had been a "mistake." She believed that her mother did not really love her. Unlike her brother and sister, who both had a baby book created for them, there was no baby book about Michelle, which reinforced her belief that her mother did not love her. As a child she had entertained thoughts of being the child of her mother's lover and not her father's child. Consequently, it was difficult for her to believe that anyone could care for her and be there for her.

Upon my return from vacation, Michelle said she felt stronger and more separate from her parents. She had always felt caught in the middle, with her mother stating that Michelle was always on her father's side, and her father buying her love with money and the attention she so desperately craved. Michelle said she felt less needy and enjoyed her alone time now in a way she had never felt before. Her recently experienced good feeling brought a new anxiety to the fore, that of being afraid to feel good and the need to be prepared for the worst. The week of feeling stronger was quickly followed by a period of anger and anxiety. Michelle feared being hurt, that someone would break into her apartment and strangle her. In exploring this with her, she recounted that, around the age of 7 , she was molested by a neighbor boy in her building who came into her bathroom while she was taking a bath and touched her genitals.

Her recent setback now was the first of many clinical regressions occurring during her treatment. Any sign of clinical improvement resulted in her dramatically losing therapeutic ground. Michelle's libidinal tie to her family was through pain and suffering. She only experienced caretaking when she was in a crisis that demanded attention. Her unhappy ideal self was the only time she was ensured concern and attention from her parents. In addition, her unconscious idealization of unhappiness may represent the struggle against identification with a devalued maternal figure. Michelle stated: "My mother had no power at home. My father denied her feelings."

Michelle had also been experiencing difficulties in her sexual relationship with her boyfriend. She felt he only wanted her physically "for my face and my body." When they would have sex, she would begin to feel as if she could not breathe and that she was being suffocated and might die. She stated that she would push him away in an angry violent fashion and felt repulsed by his advances. In exploring this feeling with her, Michelle stated that she had this experience when she had an abortion at the age of 22. I wondered whether this related to her difficulty in establishing firm boundaries for herself. Michelle reported this dream: "A friend of my sister's left her baby in the room, a bar. The baby was pale and sitting there. I try to take the baby in my arms but all these naked bodies are on the floor. I had to crawl over a naked man. The friend asked me to leave the baby alone. I'm upset. She doesn't want to take care of the baby. There was a naked man's body under me that I couldn't avoid. I was so ashamed. I touched the sexual part of the man." Michelle's associations to the dream were that: "Maybe the baby was me ... I want to be taken care of." She had no thoughts about the image of naked bodies and wanted to move away from this material. Perhaps this dream symbolized 
her growing awareness of her desire to be cared for and how she desperately sought love and affection through her promiscuity.

Although Michelle's dependent, love-seeking orientation allowed her to form a strong transference with me, she continued to complain throughout therapy that it was not helping and that she was thinking too much about herself. My role as a psychodynamic psychotherapist was to listen and interpret Michelle's resistance in an effort to help deepen her understanding of her underlying dynamics, because what happens in the transference with the therapist also happens in other relationships as well. Michelle's complaints would start as she entered the office stating that she did not want to be there. She felt that she wanted to stop and needed a break from treatment and that she was being forced to come to her sessions. This struggle can be seen as a defense against passive submissive wishes, that is, fear of fusion with an early depressed mother. This is a form of a negative therapeutic reaction, that is, negativism is a way of being close while denying the wish. Michelle reported a dream seeming to highlight this negativism: "I was with family and friends. I was in the wrong place. They were saying no. I was saying yes." Michelle continued to feel negative about treatment for the next year. Although she had the option to leave, she continued to come and complain. I began to feel depressed before her sessions and wondered what I could do to help her. It seemed that nothing I said was enough. I also found myself extending her sessions by 5 to 10 minutes in an effort to make up for her dissatisfaction with me. As patient and understanding as I felt, it did not seem to matter. Michelle seemed entrenched in devaluing treatment and wanted out. I began to feel badly for her that she had me as her therapist and felt as she did, that she had gotten short-changed. My own feelings of inadequacy proved a fertile ground for her criticisms. Supervision with a senior psychodynamic psychotherapist helped me to stay the course and respond therapeutically, nonjudgmentally, and compassionately in sessions.

In extratransferential relationships, too, Michelle stated that she was making an issue out of everything, saying the opposite of what everyone was saying and felt aggressive at work, arguing with coworkers and provoking others. She had been angry at her boyfriend and went to a party where she felt he was not paying enough attention to her, so she took off her slacks and walked around in her underpants, shocking everyone there. The following dialogue reflects Michelle's dependency and how our therapeutic relationship was reflective of her relationship with her mother in the past.

Michelle: When I feel helpless, I provoke others and this protects me. By keeping people on edge, I hurt them and it's my way to survive.

APPN: $\quad$ I wonder, do you think that could be going on here too? That you feel helpless and need to also keep me at a distance?

Michelle: (Smiles) Maybe... I do feel too dependent here. Therapy was giving me strength over the summer, but somehow, I felt relieved to not be here. But now, I don't need to come.

APPN: When in the past have you felt that way?

Michelle: I remember I would scream and cry whenever my mother came into my room. I felt robbed by her. Her presence made me feel that she was taking something away from me.

APPN: It seems that both here with me and as an adolescent with your mother, you felt similarly, that you want to push us away. Perhaps it feels scary to feel so dependent. ...

Michelle: $\quad$ Yes, I can give up everything to have someone take care of me. 
Another theme that emerged at this time was that of Michelle feeling she was doing something wrong and that I was judging her. For example, Michelle thought that her desire to quit treatment was seen by me as dumb. In exploring this with her, she remembered her father as quite critical and demanding. She recalled being taken by her father to her horseback riding lessons and then being so anxious that she would fall. He would scream that she was wasting his time and money. Michelle felt it was important for her to be able to say no to me now, that is, that she was not going to come just because I wanted her to. I agreed that it did seem important for her to be able to say no to her boyfriend and now to me. It seemed though that she was feeling about therapy as her father had about her horseback riding lessons, that it was just a waste of time and money. In exploring this with her, she expressed fears of becoming too dependent on me and felt it would be hard to leave therapy. "Since my needs aren't met in a relationship, I get frustrated." I thought that perhaps Michelle had internalized her father's harsh, critical messages.

As Christmas vacation approached, Michelle began to feel increasingly anxious, especially at night when home alone. She would be taking a bath and begin to worry that someone was going to attack her and strangle her. She also had been feeling claustrophobic and fearful in the subway. Upon questioning Michelle about the origin of these feelings, she stated that as a child she felt the same when she was shut in her room by her dad after he said goodnight. Michelle would cry and at times feel panic stricken, upon which her father would scream at her: "Take control of yourself!" Michelle's recurring paranoia seemed to coincide with her impending separation from treatment over the holidays and earlier from her separation from her father. Michelle's rage at the abandoning loved one precipitated a decompensation of ego defenses with projection of her hostile impulses. In part her paranoia stemmed from Michelle's unmet dependency needs, resulting in projected rage.

Indeed, in the next several sessions Michelle stated that she was feeling angry at me but knew that she should not be mad at me. She stated that somehow, she felt I should know what she wanted. She felt bitter and angry about coming to therapy. She had a sense of struggle, of pain, loneliness, and fragility. She felt everyone was against her. She stated: "I'm never doing the right thing." She recalled sadly feeling that her mother's lover had taken her place, with Michelle then taking her mother's place with her father. Michelle would fill in for her mother by vacationing with her father. She recalled how scared she would feel driving with her father as he would drink and drive recklessly. Once they were in an accident and she was injured and nearly killed. Michelle said that no one else would go with her father and her siblings could not understand why she went along. Thus, as a result of her mother's unavailability, Michelle was literally in life-threatening situations. It seemed that the impending separation from treatment revived abandonment feelings from her past which were closely aligned with fearful feelings based on real dangerous past situations experienced in the context of her mother's abandonment.

Another important dimension of Michelle's fear related to her feeling that something was wrong with her and that she had done something wrong. The cognitive egocentricity of childhood contributed to Michelle's pervasive guilt and her low self-esteem. Therapeutic interventions focused on questions exploring specifically how Michelle felt she had caused her mother's neglect and abandonment. I pointed out to Michelle that she had deserved better and that her mother's problems prevented her mother from being there for Michelle and that she did nothing wrong to cause her mother's neglect.

\section{Transcript of Therapeutic Interventions}

The following is a verbatim transcript from a session transcribed toward the end of Michelle's treatment. This session illustrates several psychic shifts that took place for Michelle and are elucidated in the discussion immediately following the session. 
Michelle: $\quad$ I seem to end up in these situations. I was doing my captions at work and do you remember that lady I told you about who I thought had some problems and who I thought I should keep away from? She's the one who was recently divorced from the boss.

APPN: Yes.

Michelle: Well, anyhow I was working with Barbara doing the captions and she came up and said I wasn't doing it right. She should realize that I'm new and that I don't know everything and am still learning. But no, she starts screaming at me that I've fucked it up and makes this whole big scene in front of everyone. I was so humiliated. She could have told me quietly and alone but no, she starts screaming in front of everyone and I'm so embarrassed.

APPN: $\quad$ That is a very humiliating situation. What did you say?

Michelle: $\quad$ At first, I didn't say anything. I was too stunned. Then I decided I had to say something to her, that it was important for me to talk to her. So, I asked her if I could see her alone and then told her that she could not speak to me again like that and that if she wanted to correct my work to do so without screaming and in private. She started crying and telling me all about her problems and that she was under a lot of stress and how sorry she was. I couldn't believe it. All of the sudden she's crying in my arms and confiding in me.

APPN: $\quad$ And once again you end up caretaking.

Michelle: $\quad$ Yes. Just like with my mom. She used to cry in my arms and tell me how bad things were and I never knew what to say or do. She would tell me how bad things were for her with my father. Then, that afternoon, this photographer guy from France, who's a friend of my boss, came to the office. I was joking around with him. You know goofing around and the people at work were saying why don't you go with him shopping. He said he was going to go buy a pair of jeans that afternoon. They said to him: "Why don't you take Michelle with you? She can help you pick out some jeans." I think he really wanted me to go. He said: "Yeah, come Michelle, let's go." I felt confused at first but then thought why should I go with this guy to help him out? I don't really know him and I get paid by the hour so if I leave, I'll lose out on my money. You know, what's in it for me? So, I said: "No, I'm not going."

APPN: $\quad$ It sounds like with both the woman who humiliated you at work and this man, you decided what was in your best interests and let them know and you were able to say no, I'm not going to do something that isn't good for me.

Michelle: $\quad$ Yes, I felt it was good that I did that . . (pause) I don't know. Things have been up and down lately.

APPN: What do you mean?

Michelle: $\quad$ Friday night I was so lonely and hurt. I went home and cried.

APPN: What was going on?

Michelle: $\quad$ I don't know. Nothing really had happened to make me so sad. 
APPN: $\quad$ You were here for your session that evening. How did you feel when you left?

Michelle: $\quad$ It was a good session. I didn't feel bad when I left.

APPN: $\quad$ Do you remember what you said as you were leaving?

Michelle: No.

APPN:

That the session had gone by so quickly and you could stay here forever.

Michelle: $\quad$ Yes, I remember being so surprised that the time was up. Then I went home and cried. I had a dream that night that I was in a huge apartment where the light was warm and it was comfortable. Someone came and told me that my mother was dead.

APPN: $\quad$ Anything else about the dream?

Michelle: $\quad$ No, it's funny though that I've been thinking a lot about my mother lately and I feel like for the first time I really understand that my mom wasn't there and before I knew it, but I didn't know it. Do you know what I mean?

APPN: $\quad$ I'm not sure. Tell me.

Michelle: Well, I know you have told me that so many times that she wasn't there for me, but I feel that I never really realized it before now. And, all I can say is that I see it now.

APPN: $\quad$ So maybe the dream is not about your mom physically dying but about your new awareness and acceptance of her absence in your life.

Michelle: $\quad$ Yes, I guess so.

APPN: $\quad$ Also, the setting in the dream sounds very nice. You are in a huge, warm, light apartment. Do you think that could be about some of the feelings you have been having here lately?

Michelle: $\quad$ Yes, I thought of that. Maybe. I feel I am changing and looking at things differently. I'm beginning to remember things from my childhood that I didn't remember before.

APPN: $\quad$ Oh? Tell me.

Michelle: $\quad$ About who I was and how I was laughing and having fun. I had friends who liked me and we would laugh together.

APPN: $\quad$ Tell me more about what you are remembering.

Michelle: I was thinking of my friend, Pierre, and how much fun we used to have. I was such a tomboy. He and I learned to ride our bikes together. We kept falling off and laughing and making fun of each other. We taught ourselves to ride.

APPN: $\quad$ What a spunky little girl to teach yourself to ride a bike! You know, you have told me before about learning to ride your bike but never about the fun you had doing it, only about how disappointed you were about your mom not coming down to see you ride. It is as if the disappointment and sadness about your mom not being there for you poisoned all your experiences as a child so you could not remember until now anything positive that happened. 
Michelle: $\quad$ Yes, I only felt the pain. Funny, but it's as if something is alive, what's missing is found.

\section{Commentary}

This session illustrates several intrapsychic shifts. In contrast to Michelle's previous resistance, which was manifested by her feeling forced to come to session, the overall tone of the session is quite positive with Michelle wanting to come and eager to tell me what had happened. This represents a highly significant change from her previous negative stance. I feel that our relationship revived abandonment experiences for Michelle and served as a focal point in treatment with the resulting intensification of the transference leading to subsequent therapeutic growth. The negative maternal transference of the abandoning mother served to heighten Michelle's resistance. The resistance was worked through and disproved by the reliability of the psychotherapeutic frame, that is, the consistency, structure, and reliability of the sessions, and my return after my vacations and holidays. My emotional availability, despite her negativity, disproved her transference. I was not like her inconsistent, unavailable mother. Here was a reliable, consistent, caring person whom she could count on. Michelle also experienced the choice of having phone sessions when she could not come to my office for sessions, so my availability could then be on her terms. I was not like her father who forced her to do things and be there for him. Insight derived from interpretive work, linking her distorted views of me with their origin in her childhood, promoted further ego growth. Clearer representations of herself from others emerged, leading to a kinder, more accepting view of herself. There was thus a modification of her harsh superego.

The incident at work that Michelle talks about in the session demonstrates an increase in ego strength in that Michelle has less need for approval and can withstand criticisms better and say no to the woman at work and the man, who represented aspects of both her mother and father. Her need for nurturing and dependency was so great when she entered treatment that she went along with anything in order to be loved. She illustrates in this session that she can deal with others better as they are in the here and now. Contributing to her increased ego strength is the enlargement of the sphere of her observing ego. She is able to reflect on her past dysfunctional patterns of behavior and see choices that are available. Her awareness of the genetic roots associated with her interaction with the woman and the man at work represents a relatively recent insight for Michelle.

It is also interesting in the session that Michelle demonstrates a mini therapeutic regression. She relates that she had felt good after the last session, but then went home and cried. Although nothing in reality had happened to make her feel bad, intrapsychically she retreated with each move toward autonomy, which was associated with positive transferential feelings. Michelle quickly loses therapeutic ground and regresses to her former ,more familiar self, that of feeling pain. Michelle's positive feeling about therapy is a new experience, which she has difficulty sustaining.

Michelle's dream represents an important shift for Michelle in that she is acknowledging her mother's absence in a new way, which in the past she defensively needed to deny. Michelle's guilt over having caused her mother's abandonment is abating through her understanding of her mother's own problems and Michelle's relinquishment of her denial of her mother's deficits. Her statement "I knew it but I didn't know it" demonstrates her denial and the shift in her defensive structure.

In the session, I focused on the apartment in the dream as a metaphor for Michelle's feelings about therapy. In retrospect, this may also represent her feelings about herself and the internal changes that have taken place. It is light and the apartment is huge, indicating that with the light she can see clearly. Thus, the denial is lifted and, with that, a larger intrapsychic space is created with more room for growth. The apartment 
is also warm, which may relate to Michelle's increase in positive feelings about herself. Michelle's awareness of her parents' limitations has allowed her to feel more positively about herself. Previously, she felt that she was such a bad person and that it was not her parents who were at fault.

Michelle's remembering positive things from her childhood indicates a lifting of repression has taken place. With the relinquishing of denial, she can now let in more positive feelings and memories about herself. This may be what Michelle has found, a new affective coloring of her self representation. Her previous defensive structure consisted of the use of more primitive defenses, projection, and denial while now she can sublimate her aggressive and sexual drives through her work as witnessed by a heightened interest in the creative aspect of her photography work. Michelle's expression and understanding of her anger at her parents has enabled her to own her anger and she does not need to project it onto others; thus, her paranoia has decreased. As illustrated by the verbatim session, she uses denial less and has moved toward resolution and acceptance of her mother's absence. When she entered treatment, she idealized her father and only had hostile feelings for her mother. Through the therapeutic process she became in touch with the sadism she experienced at the hands of her father.

When Michelle came to therapy, she was drowning in her own experiences. She was not able to look at her dysfunctional patterns of behavior and see how she contributed to her own unhappiness. She is now able to reflect on her experiences. She has made many gains in this area and is aware of how she transfers maternal and paternal feelings onto others. She has enlarged the sphere of her observing ego which has contributed to structuralization of her ego.

Although Michelle is still subject to clinical regressions after therapeutic gains, she is able to sustain happiness for longer periods of time. She actively pursues her own happiness and now does not wait for others to take care of her. Further ego strength is demonstrated by her ability to look after herself. She set appropriate career goals and has moved into an apartment with a roommate she likes and gets along with. Through internalization of the soothing function of the therapeutic relationship, Michelle now has the capacity to be alone and to enjoy her time alone. Previously, she became highly anxious when in her apartment alone and would frantically call her friends. When sick or feeling vulnerable, she did not know how to go about nurturing herself. She tries now to take better care of herself. Over the course of the past 2 years, she has cut back on her drinking and smoking and is now taking yoga classes that she finds helpful in relieving stress.

Michelle can now postpone gratification and regulate her emotions. Recently she waited 10 days for her boyfriend to call her. In the past, she would call her boyfriend constantly demanding attention, much as she would call her mother when she was at work. Also, Michelle's reactive approach to her environment has been modified, resulting in greater autonomy of her ego from drives. Further strengthening of her ego is illustrated by her increase in self-esteem and lessening of her need for approval. Michelle's neediness previously prevented her from using good judgment. She is now better able to say no to men and set appropriate boundaries in relationships with others. Her sexualized aggression and obsession with men was modified as she understood the needs served by her behavior. Through her work in psychodynamic psychotherapy, she has deepened her understanding of herself, thus enlarging the sphere of her observing ego. Our work together has resulted in a kinder, more compassionate relationship with not only others but toward herself. 


\section{DISCUSSION QUESTIONS}

1. Can you identify any aspects in your current relationships with others that may have arisen because of significant past relationships with your parents or siblings when you were growing up?

2. Are there any problems in your life that you think psychodynamic psychotherapy could help you deal with better?

3. Discuss aspects of a case formulation for psychodynamic psychotherapy using the table included in this chapter.

\section{REFERENCES}

Bjorklund, P. (2000). Assessing ego strength: Spinning straw into gold. Perspectives in Psychiatric Care, 36(1), 14-23. doi:10.1111/j.1744-6163.2000.tb00685.x

Cozolino, L. (2017). The neuroscience of psychotherapy: Healing the social brain (3rd ed.). New York, NY: W. W. Norton.

Gabbard, G. O. (2017). Long-term psychodynamic psychotherapy: A basic text (3rd ed.). Washington, DC: American Psychiatric Publishing.

McWilliams, N. (2011). Psychoanalytic diagnosis (2nd ed.). New York, NY: Guilford Press.

Wachtel, P. (2011). Therapeutic communication: Knowing what to say when (2nd ed.). New York, NY: Guilford Press.

Wheeler, K. (2022). Psychotherapy for the advanced practice psychiatric nurse: A how-to guide for evidence-based practice. New York, NY: Springer Publishing Company. Psychodynamic Psychotherapy: Healing Attachment Wounds 